\title{
The economics of mental health in the workplace: what do we know and where do we go?
}

\author{
DAVID MCDAID
}

\begin{abstract}
To provide an overview of the economic impact of poor mental health in the workplace and assess the extent to which economic evaluation has been used to further the case for investment in workplace based mental health programmes. Rapid scoping review of published and grey literature. The socio-economic costs of poor mental health in the workplace are substantial but conservative, as few studies have included productivity losses from work cutback, as well as absenteeism. While few economic evaluations of workplace based mental health interventions were identified, the available evidence base suggests that they have the potential to be highly cost effective. Much of this evidence may be from the US and be less applicable elsewhere; it may also have been solely published in company documents making assessment of methodological quality difficult. The potential economic case for workplace based mental health interventions appears good. More collaboration between policy makers and the private sector would help facilitate rigorous and transparent economic evaluations. A number of evaluations are planned. The challenge is to build on these initiatives, in order to address what remains a major gap in our knowledge on the economics of mental health.
\end{abstract}

\section{INTRODUCTION}

Much of the work undertaken by health economists looking at the relationship between employment and poor mental health has focused on the important issue of labour force participation by people with severe mental health problems. There have been a number of economic evaluations (admittedly US dominated) of different interventions that seek to help this group return to work, including comparisons between vocational rehabilitation and supported employment schemes (Anderson et al., 2007). In contrast, much less attention appears to have been given towards assessing the economic case for investment in the prevention, and/or early recognition and treatment in the workplace of depressive and anxiety related disorders, as well what are more commonly referred to as stress related problems.

In many respects this lack of attention is remarkable; the socio-economic impacts of poor mental health in the workplace are substantial and increasing. This article provides a brief overview of these economic conse-

Address for correspondence: Dr. D. McDaid, LSE Health and Social Care and European Observatory on Health System and Policies, London School of Economics and Political Science, Houghton Street, London, WC2A 2AE (United Kingdom).

Fax: +442079556803

E-mail: d.mcdaid@lse.ac.uk

Declaration of Interest: This editorial was prepared within the Mental Health Economics European Network Phase II project, supported by grant (SPC. 2004120) from the European Commission, Health and Consumer Protection Directorate. There is no conflict of interest. quences, looks at the recent European policy response, assesses the extent to which workplace based interventions to prevent or alleviate these problems have been the subject of economic evaluation and outlines ways in which the evidence base might be further strengthened.

\section{ECONOMIC IMPACT}

Upward trends in the levels of depression and stress related absenteeism from work can be seen right across Europe. Permanent withdrawal from the labour force is also on the rise, increasing disability and sickness benefit payments that have now become a major drain on several European social welfare systems (Curran et al., 2007). For example, around $25 \%$ of all illness-related social security expenditure in France is due to work related stress (Bejean $\&$ Sultan-Taieb, 2005). In Finland 20\% of all sickness benefits and $42 \%$ of all disability pensions are now paid out for people with mental health problems; overall around 50\% of all people recorded as suffering from depression are now on long-term disability pensions (Jarvisalo et al., 2005).

The short-term impacts on business can also be substantial. One English survey of human resource professionals conducted by the Chartered Institute of Personnel and Developmemt (CIPD) reported that $40 \%$ of all companies identified had rising levels of stress-related absenteeism. These rates were at their highest in the public sector, where $76 \%$ of respondents cited stress as a leading cause of absence in their workplace, compared with $49.6 \%$ of those based in the private sector. The average 
cost of absence, per employee per year, rose to $€ 1021$ compared with $€ 927$ in 2006 (Chartered Institute of Personnel and Development, 2007).

At population level, the economic costs of common mental health problems far outweigh their health system costs. Typically cost of illness studies of depression and anxiety related disorders report that productivity losses, due in the main to the absenteeism and lost opportunity to work, account for between $60 \%$ and $80 \%$ of all costs. One English study estimated that the total costs of adult depression in 2002 were $€ 15.46$ billion or $€ 309.2$ per head of population; treatment costs accounted for only $€ 636$ million of these costs, the vast majority of additional costs were due to lost employment because of absenteeism and premature retirement from the labour force (Thomas \& Morris, 2003).

While the costs of absenteeism and withdrawal from the workplace are relatively straightforward to identify, they may in fact be a highly conservative estimate of total productivity losses. There is a growing body of literature on the impact of 'presenteeism' or 'work cutback', whereby individuals remain at work but do not function effectively (Sanderson \& Andrews, 2006). One US study suggested that this may be five times or more greater than the costs of absenteeism (Kessler \& Frank, 1997), whilst another US study of workers with depression found that this was associated with 7.2 hours per worker per week of lost productive time, or $86 \%$ of total time losses including absenteeism (Stewart et al., 2003).

Workers experiencing stress and mental health problems are also more likely to seek early retirement (Harkonmaki et al., 2006). In Finland, Karpansalo et al. (2005) reported that employed men with depression retired almost two years earlier than their non-depressed colleagues. This increased risk of early retirement is becoming ever more critical as workforces across most of Europe age rapidly. In the absence of new additions to the labour pool, for instance through migration, those left in the workforce will potentially have to pay greater premiums and work for a longer period of time in order to fund and sustain social welfare systems. To counter this at an EU level a goal of raising the participation rate of older workers from a level of $38.5 \%$ to more than $50 \%$ has now been set (Gould \& LaitinenKuikka, 2003). Clearly, promoting and protecting the mental health of employees will help this goal be achieved.

\section{POLICY RESPONSE}

Employment has many obvious benefits. For the individual it provides an opportunity to earn a regular income and thus obtain greater long-term financial security. It can also provide social status and a sense of achievement, helping bind local communities together (Jahoda, 1981). For governments employment reduces the need for the provision of additional financial support to individuals through social welfare payments. It also helps sustain economic growth, which in turn raises tax-based revenues that can be used to support public services. Maintaining a high level of employment is also central to the key EU goal, set out in it's Lisbon agenda, of ensuring that Europe remains competitive in a global marketplace, where the revitalised Russia and the newly emerging economies of China and India represent fresh challenges.

For employers too, protecting the mental health of their workforce is integral to both remaining efficient and maintaining a good work environment. Changing working practices, which have seen a shift away from heavy industry in Europe towards a more high technology and service sector dominated economy, can create much uncertainty for workers. Patterns of working are changing: in a world of instantaneous communication consumer demands have risen inexorably; technological innovation also means that the notion of being able to hold one job for life has all but disappeared, most individuals can now expect not only to change employers but also sector of work during their lifetime.

These benefits to the health of workers, business productivity and European economic performance have increased interest in measures to tackle poor mental health in the workplace (McDaid et al., 2005). At EU level, a voluntary Framework Agreement on Work-Related Stress was signed by the European Social Partners (European associations of trades unions and employers organisations) in October 2004 (Monks et al., 2004). Its principle objective was to increase awareness among employers and employers of the signs of work related stress and to provide guidance on how to combat the issue. Early indications suggest that significant progress in introducing measures and legislation has been achieved in several EU countries, including the Czech Republic where the Agreement was put into law under 2006 Labour Code, while in some others such as Norway existing legislation already covers the areas set out in the Agreement (European Trade Union Confederation, 2007).

Another sign of the growing attention placed on mental health in the workplace has been the inclusion within the WHO Action Plan on Mental Health for Europe for work towards the creation of "healthy workplaces by introducing measures such as exercise, changes to work patterns, sensible hours and healthy management styles" and the inclusion of "mental health in programmes dealing with occupational health and safety" (World Health Organization, 2005). 


\section{ARE WORKPLACE MENTAL HEALTH PROMOTING AND PROTECTING INTERVENTIONS COST EFFECTIVE?}

It is clear that the economic impacts in the workplace of poor mental health are substantial and that there is growing interest from policy makers, business and other stakeholders in the implementation of promotion and protection strategies. It is thus important that we increase our knowledge, not only of what works and in what settings, but also at what cost. This is a question currently being addressed in detail by the 32 Country EC Supported Mental Health Economics European Network (MHEEN).

Actions taken include identification strategies to determine vulnerability in the workplace, management programmes including modifications to job structure and environment in order to tackle problems, and a range of strategies to help those who have had longer periods of time away from work reintegrate back into their workplace. However an initial scoping review suggests that, despite all the rhetoric about the economic case, there still is very little formal evaluation of the cost-effectiveness of such interventions.

Much of what is available has been conducted in the United States. This is perhaps unsurprising given that US employers are usually responsible for the health care costs of their employees (Dewa et al., 2007). For instance, one Employee Assistance Programme run by the McDonnell-Douglas company managed to reduce both work loss days by $25 \%$ and turnover by $8 \%$ of people with mental health problems (McDonnel Douglas, 1990). A number of other US based programmes focusing on promoting health as a whole, rather than mental health alone, have also been shown to be cost effective (Pelletier, 2005).

Some evaluations of effectiveness and/or cost effectiveness have taken place in Europe; measures have usually focused on traditional occupational safety and health measures, although public and private sector companies have also begun to take action to tackle stress and depression related problems in the workplace (Berkels et al., 2004). The recent CIPD survey in England, suggests that $42 \%$ of employers assert that they are developing schemes to protect mental health, acknowledging that this, in addition to the obvious health benefits, can also help improve their companies economic performance (Chartered Institute of Personnel and Development, 2007).

For example, looking at the effectiveness of screening measures in the workplace, Electicitie de France and Gaz de France have implemented the APRAND programme (Action de Prévention des Rechutes des troubles Anxieux et Dépressifs) for its 140,000 employees. The programme is designed to help in the early identification of anxiety and depressive disorders by company occupational health physicians, as well as by primary care doctors and social workers. Results indicate that, of those workers on long term sick leave identified as having anxiety or depressive disorders, the cohort that subsequently participated in additional preventative activities had an increased $10 \%$ to $20 \%$ probability of recovery or remission at twelve months, compared with those who received usual care alone. Work is now planned to determine the impact of this intervention on absenteeism rates (Godard et al., 2006).

There are also some reports documenting the economic impact of investing in programmes to tackle stress. In England, London Underground has instigated a stress reduction programme for it's 13,000 employees. Internal evaluation suggests that in the first two years of the scheme's operation, a reduction in employee absence avoided costs of more than $€ 705,000$. This was eight times greater than the level of investment into the scheme. In addition there was also evidence of improved productivity by those at work and some positive healthy lifestyle changes by employees (Business in the Community, 2005).

An older evaluation took place in a Belgian pharmaceutical company, where high levels of stress related absence were linked to the prevailing economic climate, which fuelled a sense of job insecurity. The company invested in a stress management course for those employees identified as being at risk, while also setting up training for company management on how to recognise the signs of stress. Although this evaluation concluded that gains achieved by the scheme in terms of a reduction in absenteeism were just $1 \%$, the costs avoided by the company from stress-related absenteeism were so substantial that a net gain of 600,000 was still realised (Polemans et al., 1999). This is just one of a number of company produced studies that suggest workplace mental health promoting strategies are likely to generate much greater gains than the costs of programme implementation.

Another area which has been the subject of economic evaluation in an employment context is the use of psychological therapies, particularly, cognitive behavioural therapy (CBT) for people with anxiety and depressive related disorders. One study in England concluded that the use of a computerised version of CBT would be cost effective, even at low levels of effectiveness gain, because of the positive impact treatment would have in reducing productivity losses due to absenteeism from work (McCrone et al., 2004). More recently, as part of 
the Improving Access to Psychological Therapy (IAPT) Programme launched in England in 2006, two pilot psychological therapy projects are now being evaluated in terms of effectiveness and cost effectiveness, whereby return to employment is a key outcome measure.

A slightly different but related area where research has been more longstanding is the use of mental health promoting interventions to help those who are unemployed, and who typically are then at greater risk of problems such anxiety and depression, return to employment. One of the most well known of these schemes is the JOBS programme. Developed in the US in the late 1980s, the intervention consists of a small number of training workshops that involve active learning and self-efficacy to help empower individuals to take more control over the job-search process and cope with difficulties and disappointments in this process. The programme was found to help promote reemployment and generate a positive return on investment, as the costs avoided and additional income gained were much greater than the costs of investing in the programme (Vinokur et al 1991). Subsequently it has been implemented, with some success and in different contexts, in other high-income countries around the world, including Finland, and the Netherlands. It is now the subject of ongoing evaluation in a cross border region of Ireland; again initial findings suggest that the programme has been effective. (Barry $e t$ al., 2006).

\section{CHALLENGES AND FUTURE OPPORTUNITIES}

The nature of the workplace has meant that there has often been very little incentive to put the results of economic evaluations of workplace mental health schemes into the public domain. Assessment of mental health in the workplace is clearly a sensitive issue; the stigma associated with poor mental health means that employers may be reluctant to publicise work in this area; employees and trade unions may also be guarded about participation in any evaluation for fear of individual workers being labelled as having a mental health problem and perhaps then at risk of losing their jobs.

Another continuing challenge is the difficulty in assessing the methodological quality of much of the available evidence. Studies are often reported solely in company publications. There is often little incentive to publish findings in peer-reviewed journals. Moreover, many evaluations of interventions to tackle stress available in the grey literature that suggest that they have significant net benefits, are produced by organisations which may stand to gain commercially from their more widespread use.

It is therefore in the interest of policy makers, as well as employers, to carefully consider providing financial support for workplace based mental health interventions. One option is to retrospectively add an economic dimension to existing studies of the effectiveness of interventions. Careful consideration of how interventions can be adapted to work in different settings and contexts should also be built into this analysis. The scope for more partnership work between the private and public sectors, so as to provide for support for additional rigorous and transparent effectiveness and economic evaluation of workplace interventions, is also well merited. Indeed, in many European countries the public sector is itself a major employer where interventions, including adaptations of schemes used in the private sector, could be evaluated.

There are some encouraging signs: a number of ongoing and planned economic evaluations have already been identified by MHEEN. These include economic assessment of an early intervention scheme to help prevent major depression and long-term sickness absence in the labour force in the Netherlands, assessment of the economic costs of absenteeism to a major employer in Malta and a focus on the work related consequences of poor mental health as part of mental health impact assessment developments in Portugal. The challenge now is to build on these and other initiatives, including measures targeted at small and medium sized enterprises as well as big business, in order to address what remains a major gap in our knowledge on the economics of mental health.

\section{REFERENCES}

Anderson R., Wynne R. \& McDaid D. (2007). Housing and employment. In Mental Health Policy and Practice Across Europe (ed. M. Knapp, D. McDaid, E. Mossialos, G. Thornicroft). Open University Press: Buckingham.

Barry M.M., Reynolds C. \& Sheridan A. (2006). Implementation of the JOBS programme in Ireland. Journal of Public Mental Health 5(4), 10-25.

Berkels H. (2004). Mental Health Promotion and Prevention Strategies for Coping with Anxiety, Depression and Stress Related Disorders in Europe (2001-2003). Research Report 1001. Federal Institute for Occupational Safety and Health: Bremerhaven.

Bejean S. \& Sultan-Taieb H. (2005). Modelling the economic burden of diseases imputable to stress at work. European Journal of Health Economics 50, 16-23.

Business in the Community (2005). London Underground. Stress Reduction Programme. Retrieved September 26, 2007 from http://www.bitc.org.uk/resources/case_studies/afe_hw_05_londonu.html

Chartered Institute of Personnel and Development (2007). Annual Survey Report 2007. Absence Management. Chartered Institute of Personnel and Development: London. 
Curran C., Knapp M., McDaid D., Tomasson K. \& the MHEEN Group. (2007). Mental health and employment: an overview of patterns and policies across the 17 MHEEN countries. Journal of Mental Health 16(2), 195-210.

Dewa C.S., McDaid D. \& Ettner S.L. (2007). An international perspective on worker mental health problems: Who bears the burden and how are costs addressed? Canadian Journal of Psychiatry 52(6), 346-356.

European Trade Union Confederation (2007). Implementation of the European Framework Agreement on Work-Related Stress. ETUC: Brussels.

Godard C., Chevalier A., Lecrubier L. \& Lahon G. (2006). APRAND programme: an intervention to prevent relapses of anxiety and depressive disorders. First results of a medical health promotion intervention in a population of employees. European Psychiatry 21 (7), 451-459.

Gould R. \& Laitinen-Kuikka S. (2003). Current trends in disability pensions in Europe. In Proceedings from a Seminar Held in Helsinki on 8 April 2003. Finnish Centre for Pensions: Helsinki.

Harkonmaki K., Lahelma E., Martikainen P., Rahkonen O. \& Silventoinen K. (2006). Mental health functioning (SF-36) and intentions to retire early among ageing municipal employees: the Helsinki Health Study. Scandinavian Journal of Public Health 34(2), 190-198.

Jahoda M. (1981). Work employment and unemployment: Values theories and approaches in social research. American Psychologist 36, 184-191.

Jarvisalo J., Andersson B., Boedeker W. \& Houtman I. (Eds.) (2005). Mental Disorders as a Major Challenge in the Prevention of Work Disability: Experiences in Finland, Germany, the Netherlands and Sweden. Social Insurance Institution: Helsinki.

Karpansalo M., Kauhanen J., Lakka, T.A., Manninen P., Kaplan G.A. \& Salonen J.T. (2005). Depression and early retirement: prospective population based study in middle aged men. Journal of Epidemiology and Community Health 59(1), 70-74.

Kessler R.C. \& Frank R.G. (1997). The impact of psychiatric disorders on work loss days. Psychological Medicine 27, 861-873.

McCrone P., Knapp M., Proudfoot J., Ryden C., Cavanagh K., Shapiro D.A., Ilson S., Gray J.A., Goldberg D., Mann A., Marks I., Everitt
B. \& Tylee A. (2004). Cost-effectiveness of computerised cognitive-behavioural therapy for anxiety and depression in primary care: randomised controlled trial. British Journal of Psychiatry 185(1), 55-62.

McDaid D., Curran C. \& Knapp M. (2005). Promoting mental well-being in the workplace: a European policy perspective. International Review of Psychiatry 17(5), 365-373.

McDonnell Douglas Corporation and Alexander Consulting Group (1990). McDonnell Douglas Corporation Employee Assistance Program Financial Offset Study, 1985-1989. McDonnell Douglas Corporation, Westport, CT, and Alexander Consulting Group: Bridgeton, $\mathrm{MO}$

Monks J., Strube J., Reckinger P. \& Plassman R. (2004). Framework Agreement on Work Related Stress. European Social Partners: Brussels.

Pelletier K.R. (2005). A review and analysis of the clinical and cost-effectiveness studies of comprehensive health promotion and disease management programs at the worksite: Update VI 2000-2004. Journal of Occupational and Environmental Medicine 47, 10511057.

Poelmans S., Compernolle T., De Neve H., Buelens M. \& Rombouts J. (1999) Belgium: A pharmaceutical company. In Preventing Stress, Improving Productivity: European Case Studies in the Workplace (ed. M. Kompier and C.L. Cooper), pp.121-148. Routledge: London.

Sanderson K. \& Andrews G. (2006). Common mental disorders in the workforce: recent findings from descriptive and social epidemiology. Canadian Journal of Psychiatry 51(2), 63-75.

Stewart W.F., Ricci J.A., Chee E., Hahn S.R. \& Morganstein D. (2003). Cost of lost productive work time among US workers with depression. Journal of the American Medical Association 289, 3135-3144.

Thomas C. \& Morris S. (2003). Cost of depression among adults in England in 2000. British Journal of Psychiatry 183, 514-519.

Vinokur A.D., van Ryn M., Gramlich E. \& Price R.H. (1991). Long-term follow-up and benefit-cost analysis of the JOBS program: a preventive intervention for the unemployed. Journal of Applied Psychology 76 (2), 213-219.

World Health Organization (2005). Mental Health Declaration for Europe. Facing the Challenges, Building Solutions. WHO: Copenhagen. 